\title{
Simulation Model of Heat Generation and Transfer in Oil-Hydraulic System
}

\author{
Koki TOMIOKA*, Kazuhiro TANAKA*, Katsuya NAGAYAMA*, Kimishiro TOKUDA* \\ * Department of Mechanical Information Science and Technology \\ Kyushu Institute of Technology \\ 680-4 Kawazu, Iizuka-city, Fukuoka, 820-8502, JAPAN \\ (E-mail: tomioka@vortex.mse.kyutech.ac.jp)
}

\begin{abstract}
Recently an oil-hydraulic system has been compact and high-pressurized and that causes the steep rise of the system temperature because of the small heat volume. When the system temperature has risen so much, characteristics of the working oil deteriorate and the system will be dangerous finally.

It is very important to study a simple and precise way to predict the temperature rise of the system. The lost power rises the system temperature. Bondgraph method is convenient to predict power loss because the method is based on the concept of power transmission. Consequently, the Bondgraph method is very available to predict the system temperature rise of oil-hydraulic systems.

The oil-flow dynamics with the heat generation mechanism was modeled one-dimensionally using ordinary differential equations by Bondgraph method, which is very convenient for modeling and simulation of heat generation. On the other hand, the heat transfer in the housing was analyzed three-dimensionally using the partial differential equation of heat conduction. The prediction of the temperature distributions were calculated effectively by coupling these two kinds of equation systems. In the present paper, this prediction method is applied to a real oil-hydraulic system. The simulation result was compared with the experimental results and they agreed very well.
\end{abstract}

\section{KEY WORDS}

System dynamics, Coupled Analysis, Bondgarph Method, Heat Transfer, Oil-Hydraulic system

\section{Nomenclature}

$A$ : Cross-section Area

$A_{h}:$ Surface Area of the Housing

$c$ : Specific Heat

$d$ : Diameter of the Pipe

$d t$ : Time Step

$E$ : Internal Energy

$G r$ : Grashof Number

$g$ : Acceleration of Gravity

$h$ : Heat Transfer Coefficient

$K$ : Bulk Modulus

$L \quad$ : Characteristic Length

$l$ : Length of the Component

$N u$ : Nusselt Number

$P$ : Pressure

$P r$ : Prandtle Number

$Q$ : Volume Flow Rate

$\dot{q}$ : Work of Heat Transfer
Re : Reynolds Number

$T$ : Temperature

$T_{a m b}:$ Ambient Temperature

To : Torque

$T_{\text {wall }}$ : Temperature of the Wall

$V$ : Volume of the Component

$V_{t h}$ : Thrust Volume per One Revolution

$W$ : Work of Working Oil

$\beta$ : Coefficient of Thermal Expansion

$\Gamma$ : Thermal Diffusivity

$\delta:$ Kronecker Delta

$\lambda$ : Thermal Conductivity

$\mu$ : Viscosity Coefficient

$\rho$ : Density

[-]

$[\mathrm{K}]$

[K]

$[\mathrm{Nm}]$

[K]

$\left[\mathrm{m}^{3}\right]$

$\left[\mathrm{m}^{3} / \mathrm{rev}\right]$

[W]

$[1 / \mathrm{K}]$

$\left[\mathrm{m}^{2} / \mathrm{s}\right]$

$[-]$

[W/mK]

$[\mathrm{kgm} / \mathrm{s}]$

$\left[\mathrm{kg} / \mathrm{m}^{3}\right]$

\section{INTRODUCTION}

$\mathrm{Pa}$

$[-]$

$\left[\mathrm{m}^{3} / \mathrm{s}\right]$

[W]

Recently an oil-hydraulic system has been made which 
is compact and high-pressurized. In high-load drive state as well as low-load drive state and long time drive state, the system temperature is apt to rise steeply because of the small heat volume, heat release area and large heat generation. As a result, temperature of working oil becomes higher, characteristics of working oil deteriorate and the system is finally dangerous. Therefore, it is important to predict heat generation and heat transfer in the system for secure drive. At all, it is necessary to verify result of design by experiments. As the experimental cost is high, however, it is expected to design using numerical calculation for low cost.

In order to obtain heat characteristics of the system using numerical calculation, it is necessary to consider heat generation in oil passages and valves, heat conduction through the housing and heat transfer to the air, etc. So, for the designing this system, three dimensional modeling is necessary to predict the heat generation and heat transfer. However, the shape of the system is very complex and precise three dimensional modeling needs much calculating time. Hence, this long calculation time is not useful for designing.

Studies on the heat generation and heat transfer in oil-hydraulic systems have been performed by many researchers. For example, Johansson et al. ${ }^{(1)}$ investigated the temperature distribution in an aerospace actuation system. Yamamoto et al. ${ }^{(2)}$ studied the heat generation and temperature distribution in an oil-hydraulic system of a mobile crane. However in all of them based on one-dimensional modeling with lumped parameter systems, the prediction of the temperature distribution is not enough accurate for design a real system and components though it is important to know roughly the characteristics of the system.

In this study, the oil-flow dynamics with the heat generation mechanism was modeled one-dimensionally using ordinary differential equations by Bondgraph method, which is very convenient for modeling and simulating of heat generation because the method is based on the power transmission. On the other hand, the heat transfer in the pump housing was analyzed three dimensionally using the partial differential equation of heat conduction. The prediction of the temperature distributions were calculated effectively by coupling these two kinds of calculation systems.

In the present paper, this coupled method is performed in a simple model such as an oil-pipe. Then, this method is applied to a real oil-hydraulic system which consists of pipes and a pump etc. Comparing calculation results with experimental results, verifies this method in the system.

\section{METHOD OF COUPLED ANALYSIS}

\section{Model of heat balance}

A pipe is a basic and indispensable component in an oil-hydraulic system. Temperature of each pipe component is simulated by heat balance among the heat generation in the component, the heat transfer from the pipe wall to the internal oil and heat transportation between the neighboring components of the pipe. The diagram of this heat balance is shown in Fig. 1. In this figure, subscript $i$ indicates the index of a pipe component, $i-1$ indicates the index of the upstream side component and $i+1$ indicates the downstream side component.

Assuming that working oil dose not work to the outside of the pipe component $i$, rate of internal energy increase is expressed as follow.

$$
\frac{d E_{i}}{d t}=\left(P_{i-1} Q_{i-1}+c_{v} \rho Q_{i-1} T_{i-1}\right)-\left(P_{i} Q_{i}+c_{v} \rho Q_{i} T_{i}\right)+\dot{q}_{i}
$$

Temporal energy change in the pipe component $i$ using its temperature is expressed as follow.

$\frac{d E_{i}}{d t}=c \rho V_{i} \frac{d T_{i}}{d t}$

It is assumed that working oil is incompressible fluid, following equation is derived from equation (1) and (2).

$$
\frac{d T_{i}^{n}}{d t}=\frac{1}{c \rho V_{i}}\left\{\left(P_{i-1}-P_{i}\right)^{n} Q^{n}+c \rho Q^{n}\left(T_{i-1}-T_{i}\right)^{n}+\dot{q}_{i}^{n}\right\}
$$

where, subscript $n$ indicates iteration time. In the above equation, the first term of right-hand side indicates lost power or heat generation based on pressure loss in the pipe component $i$, the second term indicates heat transportation from the upstream side component, and the third term $\dot{q}$ indicates expressed by the following equation.

$\dot{q}_{i}^{n}=h A_{h}\left(T_{\text {wall }}-T_{i}^{n}\right)+\lambda A \frac{T_{i-1}^{n}-2 T_{i}^{n}+T_{i+1}^{n}}{l}$

where, the first term of right-hand side is heat transfer between inner wall of pipe and working oil effects and the second term is heat conduction between neighboring components of pipe.

\section{Method of data-exchange}

For the coupled calculation, the temperature data are exchanged between Bondgraph-program (Here after BG-Program) and FEM-program at the interface such as the pipe inner wall surface. This technique is illustrated in Fig. 2, in which a room partitioned by solid lines corresponds to $i$ th component in the Bondgraph model of the pipe inside. Top side indicates the pipe housing and is divided into many elements for FEM-program. Generally the number of element in FEM-program is still more than that in BG-program. FEM-program is 


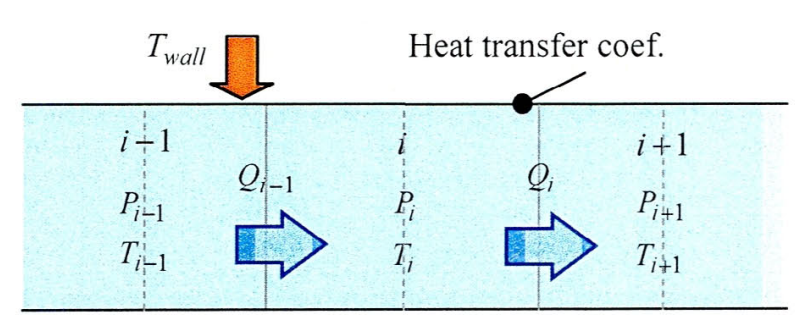

Fig. 1 Heat Balance

three dimensional and BG-program is one dimensional. In exchanging the data on the interface, the mean value of temperature distributed in the elements facing $i$ th component in Bondgraph model is given to BGprogram as the additional input temperature of the component.

And, the new temperature is calculated in $i$ th Bondgraph component through Eq. (3) in BG-program. From the new temperature, new heat flux is calculated and given to FEM-program as the boundary condition. Because the time constant is quite different between BG-program and FEM-program, FEM-program is run once a $10^{3}-10^{4}$ iterations of $\mathrm{BG}$-program. By repeating this calculation circuit, the system dynamic characteristics inside the pipe and temperature distributions in the pipe housing are calculated simultaneously.

\section{COUPLED ANALYSIS IN AN OIL-PIPE}

\section{Analysis model}

Fig. 3 shows a pipe as a simple test model for the coupling. The pipe length is $500[\mathrm{~mm}]$, inside diameter of the pipe is $10[\mathrm{~mm}]$, outside diameter is $25[\mathrm{~mm}]$, and thickness of the pipe housing is $7.5[\mathrm{~mm}]$. Table 3 shows parameters used in this analysis.
Table 1 Analysis conditions for coupled analysis

\begin{tabular}{|l|l|}
\hline $\begin{array}{l}\text { Initial } \\
\text { condition }\end{array}$ & $\begin{array}{l}\text { Pipe housing: } T=100\left[{ }^{\circ} \mathrm{C}\right] \\
\text { Working Fluid: } T=20\left[{ }^{\circ} \mathrm{C}\right], P=0[\mathrm{~Pa}], \\
Q=0\left[\mathrm{~m}^{3} / \mathrm{s}\right]\end{array}$ \\
\hline $\begin{array}{l}\text { Boundary } \\
\text { condition }\end{array}$ & Inlet: $u=0.1[\mathrm{~m} / \mathrm{s}]$ Outlet: $P=0[\mathrm{~Pa}]$ \\
\hline Time step & FEM: $d t=0.1[\mathrm{~s}] \quad$ BG: $d t=1.0 \mathrm{E}-6[\mathrm{~s}]$ \\
\hline & $\begin{array}{l}\text { Pipe housing: } \lambda=16[\mathrm{~W} / \mathrm{mK}] \\
\rho=7920\left[\mathrm{~kg} / \mathrm{m}^{3}\right], c=499[\mathrm{~J} / \mathrm{kgK}]\end{array}$ \\
$\begin{array}{l}\text { Physical } \\
\text { property }\end{array}$ & $\begin{array}{l}\text { Working fluid: } K=6.89 \mathrm{E}+8[\mathrm{~Pa}] \\
\mu=0.021[\mathrm{Pas}], \lambda=0.135[\mathrm{~W} / \mathrm{mK}]\end{array}$ \\
\hline $\begin{array}{l}\text { Heat tranfer } / \mathrm{mK}] \\
\text { coefficient }\end{array}$ & $\begin{array}{l}\text { Housing to Air: Adiabatic } \\
\text { Housing to Oil: } h=104.5\left[\mathrm{~W} / \mathrm{m}^{2} \mathrm{~K}\right]\end{array}$ \\
\hline
\end{tabular}

\section{Bondgraph model of the oil passage}

The Bondgraph model which is expresses an oil passage is shown in Fig. 4. In this figure, SF element corresponds to the inlet velocity as the boundary condition, SE element to the outlet pressure similarly, C elements to the volume effect of working oil and $\mathrm{R}$ elements to the pressure loss which causes heat generation by the wall friction. One component of pipe inside is represented by a pair of $\mathrm{C}$ and $\mathrm{R}$ elements. In this model, the pipe inside is divided into four components. In this case, the inertial effect of the oil column is ignored.

Characteristic equations in $\mathrm{C}$ and $\mathrm{R}$ elements are represented as the Eqs. (5) and (6), respectively.

$$
\begin{aligned}
& P=\frac{K}{V} \int Q d t \\
& Q=\frac{\pi d^{4}}{128 \mu l} \Delta P
\end{aligned}
$$

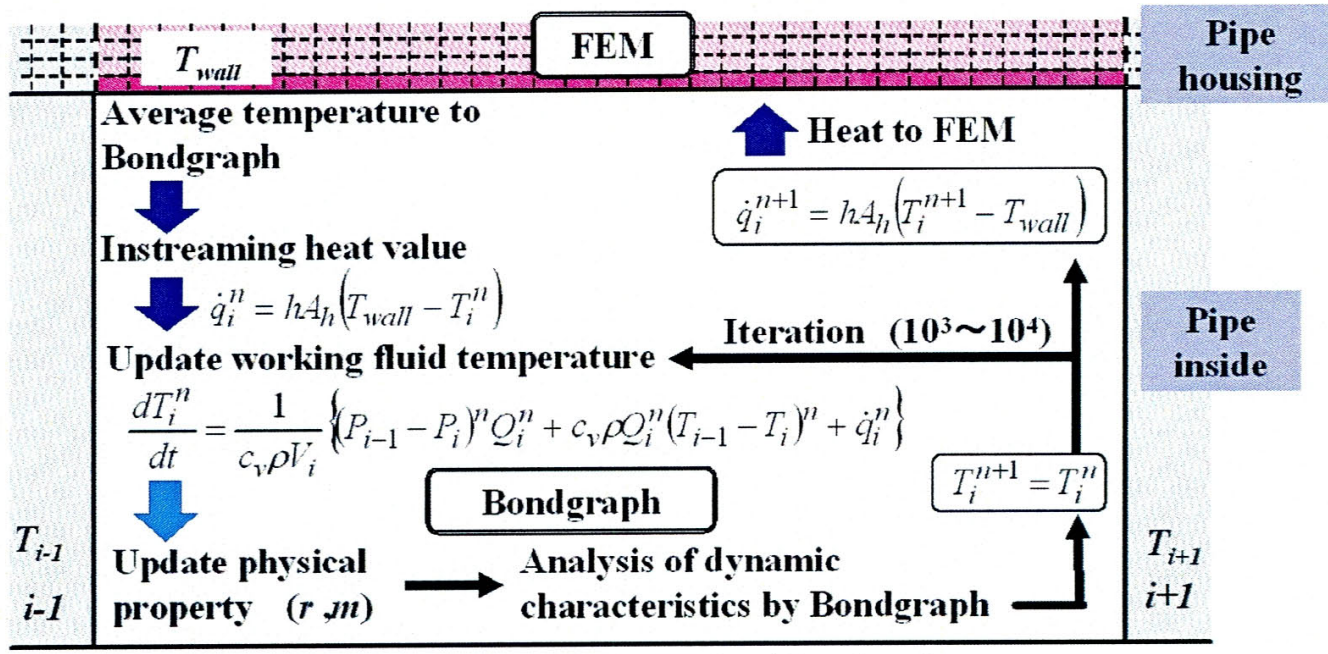

Fig.2 Interface between FEM and Bondgraph 


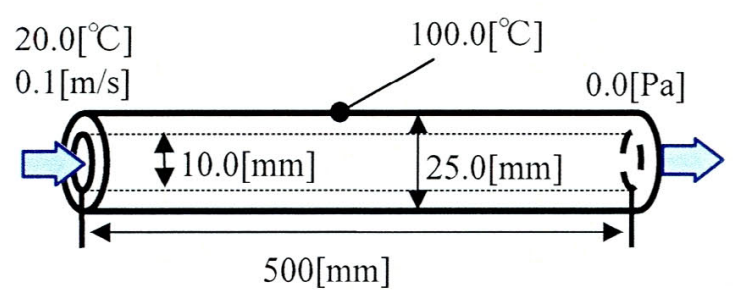

Fig. 3 Test model for coupled analysis

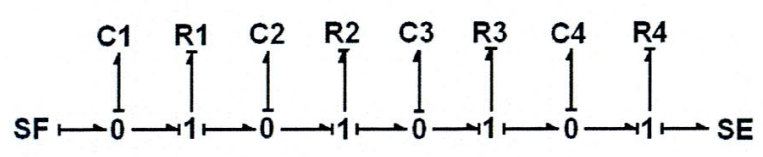

Fig. 4 Bondgraph model

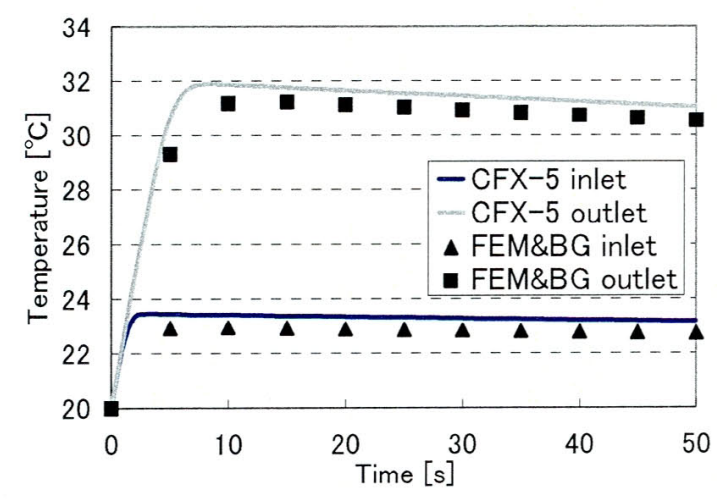

Fig. 5 Temperature change at inlet and outlet

Eq. (5) indicates the volume effect in each component and Eq. (6) the relationship between the pressure loss and the flow rate.

\section{CFX-5}

CFX-5, a commercial code for thermo-fluid flow analysis, is used in this study to verify the results through BG-method. Governing equations of CFX-5 are the Navier-Strokes equations, the energy equation, the continuity equation and the heat conduction equation. By calculating these equations, the distribution of velocity, pressure and temperature in the fluid are obtained. Heat conduction equation solves temperature distributions in the housing. Power loss of the working oil is easily obtained from the dissipation function in the continuity equation. Discretization of these equations is performed along finite volume method and tetra-mesh is used as a mesh type.

\section{Condition}

Temperature of the pipe housing is anywhere $100\left[{ }^{\circ} \mathrm{C}\right]$ and that of working oil is $20\left[{ }^{\circ} \mathrm{C}\right]$ as the initial condition. As the boundary condition at the inlet the velocity is $0.1[\mathrm{~m} / \mathrm{s}]$ and the temperature is $20\left[{ }^{\circ} \mathrm{C}\right]$. At the outlet the pressure is $0.0[\mathrm{~Pa}]$. The external wall surface of pipe housing is adiabatic. Heat conductivity of the housing and working oil are $16[\mathrm{~W} / \mathrm{mK}]$ and $0.135[\mathrm{~W} / \mathrm{mK}]$, respectively. Heat transfer coefficient between the housing and the working oil is $104.5\left[\mathrm{~W} / \mathrm{m}^{2} \mathrm{~K}\right]$. In this calculation, mesh type is tetra-mesh, the number of elements 32000, and that of nodes 7000 . The result through this coupled calculation technique (hereafter FEM\&BG) is compared with result of CFX-5.

\subsection{Results}

Fig. 5 shows the comparison between FEM\&BG and CFX-5 on temperature change of working oil at the inlet and outlet. Abscissa and ordinate axis are expressed time $[\mathrm{s}]$ and temperature $\left[{ }^{\circ} \mathrm{C}\right]$, respectively. Triangle and square symbols indicate the results by FEM\&BG and the solid line the results by CFX-5. Black and gray line and symbols indicate the temperature at the inlet and the outlet. Here the temperature represented by triangle and square symbols means the temperature averaged in Bondgraph components at the inlet and outlet, respectively. These results have the same tendency and the temperature difference between FEM\&BG and CFX -5 is not more than $\left.1.0{ }^{\circ} \mathrm{C}\right]$. These results proved the availability of coupled analysis with FEM\&BG.

\section{THERMAL ANALYSIS OF REAL SYSTEM}

\section{Real system}

Fig. 6 shows a real circuit for this study. This system consists of an axial piston pump, pipes and a cylinder. Highly-pressurized working oil flows from the pump to the cylinder through pipes (1) and (3). The working oil with low pressure in the cylinder flows out from the cylinder rod chamber to the pump through pipes (4), (7) and 8 .

In this analysis, the supplied pressure balances load of the cylinder so that the cylinder rod keeps the same position. In this driving state, working oil dose not flow in the high pressure side (pipes (1) and (3)). Consequently, working oil circulates in the leakage pipe (5) in Fig. 6), a valve ((6) in Fig. 6), the low pressure side (7) in Fig. 6) and return line of the circuit (8) in Fig. 6). System dynamics of working oil is considered in (5), (6), (7) and (8), modeled using Bondgraph. The pump housing is modeled using FEM.

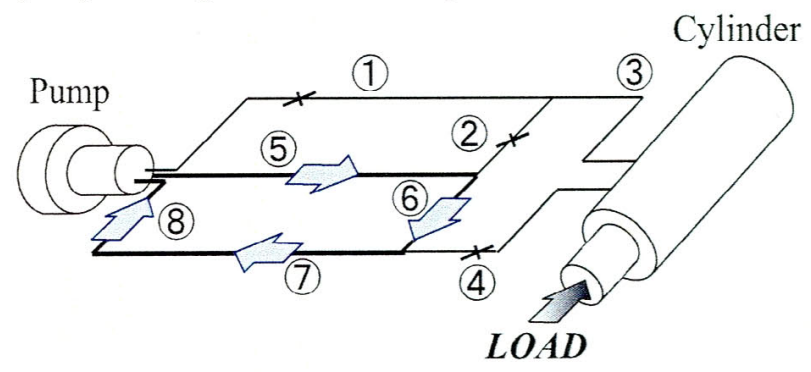

Fig. 6 Real system 


\section{Bondgraph model}

Fig. 7 shows a system Bondgraph model of dynamic characteristics of the working oil in (5), (6), (7) and (8). Table 2 shows characteristic equations which are used in each element of Bondgraph. In addition, $L O A D$ in the Table 2 changes temporally, and the detail of the $L O A D$ is shown in Table 3.

Table 2 BG-elements and their characteristic equations

\begin{tabular}{|l|l|l|}
\hline \multicolumn{1}{|c|}{ Components } & Elements & \multicolumn{1}{|c|}{ Equations } \\
\hline $\begin{array}{l}\text { Pump of high pressure } \\
\text { side }\end{array}$ & $\mathrm{SE} 1$ & $P=L O A D$ \\
\hline $\begin{array}{l}\text { Pump of low pressure } \\
\text { side }\end{array}$ & $\mathrm{SE} 2$ & $P=P_{0}$ \\
\hline $\begin{array}{l}\text { Pressure loss effect of } \\
\text { the pump }\end{array}$ & $\mathrm{R} 1$ & $Q=\frac{C_{s} V_{t h}}{2 \pi \mu} \Delta P$ \\
\hline $\begin{array}{l}\text { Pressure loss of the } \\
\text { pipe }\end{array}$ & $\begin{array}{l}\mathrm{R} 2, \mathrm{R} 3, \\
\mathrm{R} 4, \mathrm{R} 5\end{array}$ & $Q=\frac{\pi d^{4}}{128 \mu l} \Delta P$ \\
\hline $\begin{array}{l}\text { Volume effect of the } \\
\text { pump }\end{array}$ & $\mathrm{C} 1$ & $P=\frac{K}{V} \int Q d t$ \\
\hline $\begin{array}{l}\text { Pipe volume effect of } \\
\text { the pipe }\end{array}$ & $\begin{array}{l}\mathrm{C} 2, \mathrm{C} 3, \\
\mathrm{C} 4\end{array}$ & $P d t$ \\
\hline
\end{tabular}

\section{FEM model}

The housing of the axial piston pump is modeled using FEM. The grid of its pump is shown in Fig. 8. The number of elements and nodes are 22,600 and 5,600, respectively.

\section{Analysis condition}

\section{Torque loss in the pump}

Because mechanics of the axial piston pump is very complex. The component and the inside working oil are integrated as a one heat source as the simple model. The axial piston pump generates torque loss which is caused by mechanical friction loss and fluid loss. This torque loss is expressed by following equation.

$$
\Delta T o=C_{v} \mu n V_{t h}+\frac{C_{f} V_{t h} \Delta P}{2 \pi}
$$

In the above equation, the first and second term of right-hand side indicates viscous friction loss and the mechanical friction loss, respectively.

\section{Heat release from the pipe}

Oil flows inside of the pipe due to leakage from the axial piston pump. So, heat transfer (Nusselt number) from the working oil to the pipe housing is expressed by following equation.

$$
N u=0.023 \operatorname{Re}^{0.8} * \operatorname{Pr}^{0.333}
$$

Eq. (8) is Colburn's formula which means heat transfer by forced convection.

Flow of air around the pipe housing is caused by natural convection. So, heat transfer (Nusselt number) through the pipe housing to the ambient air is expressed by following equation.

$$
N u=0.53(G r * P r)^{0.25}
$$

Eq. (9) is empirical formula which means heat transfer by natural convection for the circular shape. Grashof number in Eq. (9) is calculated by following equation.

$$
G r=\frac{g \beta\left(T_{a m b}-T_{w a l l}\right) L^{3}}{v^{2}}
$$

Heat conduction of the pipe housing is ignored in this analysis because, its thickness is only $1.0[\mathrm{~mm}]$. But, heat capacity of the pipe housing is considered in this calculation. Table 3 shows parameters used in this analysis.

Table 3 Analysis Parameters

\begin{tabular}{|l|l|}
\hline Parameters & Amount of Parameter \\
\hline Pipe length & $L: 3.0[\mathrm{~m}]$ \\
\hline \multirow{2}{*}{ Time step } & FEM : 1.0E-1 [sec] \\
& Bondgraph: $1.0 \mathrm{E}-4[\mathrm{sec}]$ \\
\hline \multirow{4}{*}{$\begin{array}{l}\text { Physical } \\
\text { property }\end{array}$} & - Pump Housing- \\
& $\rho: 2688.0\left[\mathrm{~kg} / \mathrm{m}^{3}\right], c: 905.0[\mathrm{~J} / \mathrm{kgK}]$, \\
& $\lambda: 273.0[\mathrm{~W} / \mathrm{mK}]$
\end{tabular}

\section{Results}

Fig. 9 shows temperature change at the axial piston pump. In this figure, black line shows numerical analysis result and gray line shows experimental result. Abscissa and ordinate axes are time [min] and temperature $[\mathrm{K}]$, respectively. Temperature change of the pump becomes steady state at 190 minutes, and in 
this state, temperature is about 353 [K]. After 190[min], temperature of the pump is decreasing due to pressure of the pump is decreasing. Numerical and calculation results have the same tendency, and they agreed very well.

Fig. 10 shows flow late of leakage which is generated from the pump. In this figure, black line shows numerical analysis result and gray line shows experimental result, respectively. Abscissa and ordinate axes are time [min] and leakage [cc/min], respectively. In these results, leakage from the pump increases as time advances until $190[\mathrm{~min}]$. After that, decreasing load of the cylinder, leakage of the pump decreases due to pressure of the pump decreases. These results are agreed very well.

\section{CONCLUSIONS}

In this study, the housing of the axial piston pump is modeled by FEM and dynamic characteristic of working oil is modeled by Bondgraph method. And a new analysis method coupling BG- and FEM-program has been proposed. In this study, calculation results agree well with the experimental results. So, the proposed coupled analysis has been verified useful.

This coupling calculation technique can save much computing time than that through a commercial code. It can effectively be applied to solve system dynamics and heat problems in many real oil-hydraulic systems.

\section{ACKNOWLEDGEMENT}

The authors would like to thank Nabtesco Corporation for providing the experimental data and helpful suggestions.

\section{REFERENCE}

1. JOHANSSON Björn et al., Thermal modeling of an Electro Hydrostatic Actuation System, Recent Advance in Aerospace Actuation System and Components, June 13-15, 2001, Toulouse, France.

2. K. YAMAMOTO, K. TANAKA, M. NAKANISHI and S. TARUMI, Analysis of Dynamic Behavior of a Hydraulic and Pneumatic Suspension Including Temperature Change Effect, Proc. of 5th Tri.Int. Symp. on Fluid Control, Measurement and Visualizatio (FLUCOME97), Vol. 1, 457/462, Sept. 1-4, 1997,

Hayama, Japan.

3. K. TOMIOKA et al., Prediction of Heat Generation and Transfer in an Oil-Hydraulic Pipe, The Sixth KSME- JSME Thermal and Fluids Engineering Conference, 2005.

4. JSME Data Book : Heat Transfer 4th Edition, 1986.

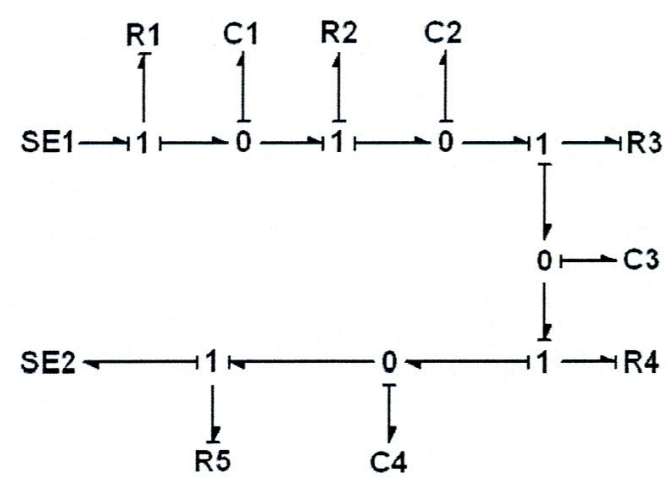

Fig. 7 System bondgraph model

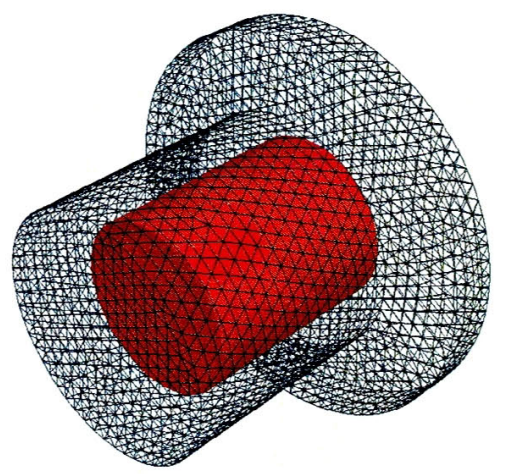

Fig. 8 Computational grid for pump housing

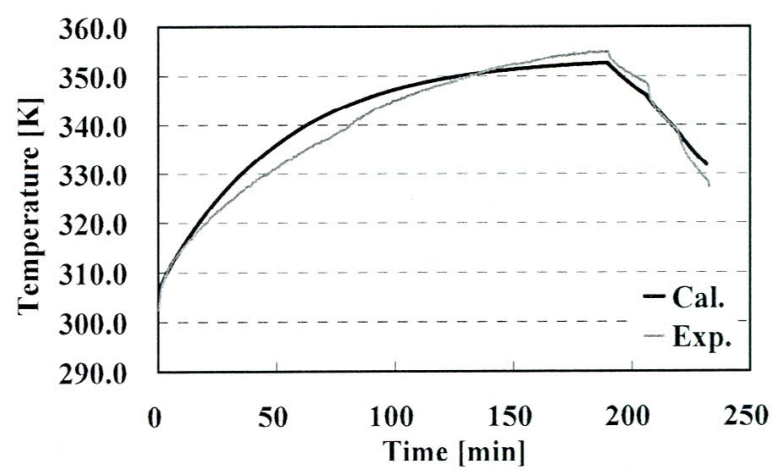

Fig. 9 Temperature change of the Pump

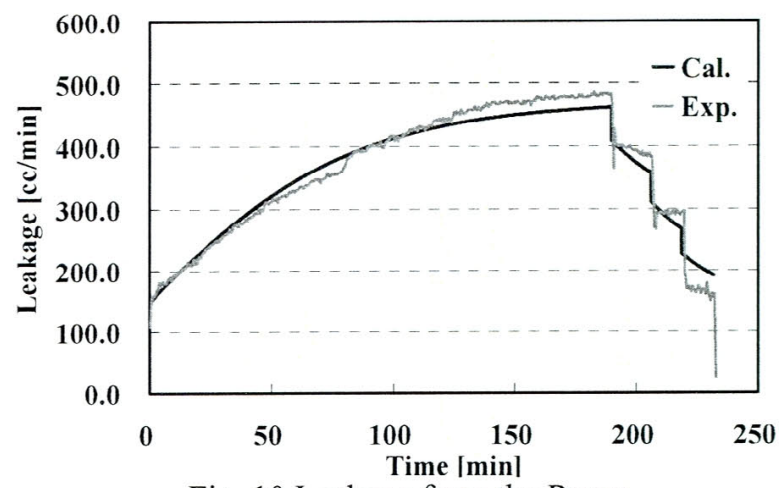

Fig. 10 Leakage from the Pump 